\title{
Diagnostic Role of Preoperative Pure Tone Audiometry in Locating Type of Ossicular Chain Dysfunction in Chronic Suppurative Otitis Media
}

\author{
Bhavya B M*, Ashish U Katarkar, Kirti P Ambani, Trupti U Bhat, T Saikrishna Teja \\ Department of Otorhinolaryngology, GMERS Medical College \& Civil Hospital, Gandhinagar, Gujarat, \\ India
}

Received Date: May 27, 2021; Accepted Date: June 08, 2021; Published Date: June 17, 2021

"Corresponding author: Bhavya B M, 151, SAPTHASHRI, Bodhanahosahally, Off ITPL Main road, Bengaluru560067, Karnataka, India. Tel: +919902931138; Email: anupamamreddy@ gmail.com

\section{Abstract}

Chronic otitis media is a common cause of acquired hearing impairment in developing countries. Pure tone audiometry is the most commonly done test to evaluate hearing sensitivity. Since ossicular status is found only intraoperatively we designed this study to evaluate preoperative pure tone audiometry findings in patients with CSOM and its correlation with intraoperative findings. Knowing the ossicular chain status is very important in patients undergoing tympanoplasty which will help in planning ossicular chain reconstruction.

Aims and Objective: To evaluate the efficacy of preoperative pure tone audiometry as a predictor in locating the type of ossicular chain dysfunction seen intraoperatively in patients with chronic suppurative otitis media. To assess the degree and type (frequency) of hearing loss in ossicular chain defects in patients with chronic supportive otitis media.

Material and Methods: It is a Cross sectional study, included 115 cases of CSOM, both tubo-tympanic and attico-antral type who underwent PTA as a routine hearing evaluation preoperatively. Pure tone averages, ABG, ACT at $500 \mathrm{~Hz}$, $1000 \mathrm{~Hz}, 2000 \mathrm{~Hz}, 4000 \mathrm{~Hz}$ were compared with intraoperative ossicular chain status.

Results: Out of 115 cases, 81\%weretubo-tympanic, 19\%atticoantralCSOM.Atticoantral CSOM had higher incidence of ossicular chain defects. Frequency specific ABG, ACT values were statistically significant $(\mathrm{p}<0.05)$.Higher degree of hearing loss was seen with Austin type B and D ( $p=0.026)$.
Conclusion: Frequency specific ABG and ACT can be reliable parameters on basis of which we can predict ossicular status preoperatively.

Keywords: Chronic Suppurative Otitis Media; Ossicular Chain Defects; Pure Tone Audiometry; Air Bone Gap

\section{Introduction}

Chronic suppurative otitis media (CSOM) is a wide spread disease of developing countries like India especially in rural areas, prevalence ranges from 2 to $15 \%$ attributed to poor hygiene, poor living conditions, overcrowding, malnutrition, and inadequate healthcare [1]. CSOM is recurrent, progressive disease presents with suppurative discharge and middle ear structural abnormalities like perforated tympanic membrane, ossicular chain pathologies ranging from partial necrosis to complete loss, ossicular chain fixation due to tympanosclerosis, soft tissue pathologies like cholesteatoma, granulation tissue, mucosal polyps, and cholesterol granulomas [2].

CSOM is the leading cause of acquired conductive hearing impairment in adults [3]. Ossicular erosion is a frequent complication that occurs in $>50 \%$ cases of CSOM, more common in attico antral type, which leads to total failure of middle ear mechanics and results in substantial hearing loss [4,5]. Ossicular chain dysfunction can be ossicular chain fixation or discontinuity (gross or functional discontinuity). Longer duration of the disease, greater the degree of hearing loss $[6,7]$, Complete disruption of ossicular chain can result in $60 \mathrm{~dB}$ hearing loss, and higher rate of long-term acoustic failure up to $50 \%[8,9]$. Myringoplasty in the absence of ossicular 
damage is bracketed with a much higher long-term success rate $>90 \%$ even in wet ears [10].

Hearing restoration is possible when the ossicular chain status is diagnosed preoperatively which helps the surgeon to plan the surgery. However, Ossicular integrity can only be confirmed intraoperatively [11]. Pure tone audiometry is a routine preoperative procedure done to evaluate auditory sensitivity before tympano-mastoidectomy. While HRCT temporal bone can assess the ossicular integrity, is expensive and less widely used. Pure tone audiometry can play an important role in predicting the severity of hearing loss which in-turn reflects on the integrity of tympano-ossicular system. Audiometry graph with narrow $\mathrm{ABG}$ at lower frequencies suggests absence of ossicular dysfunction and wide ABG at higher frequencies suggests ossicular dysfunction. This will help the surgeon in preoperative planning before tympanoplasty surgery. The patient can also be informed regarding their hearing status and counselled about the results of the surgery $[12,13]$.

Considering the importance of ossicular chain in reconstruction of transmission mechanism of the middle ear, the present study was undertaken to evaluate the efficacy of preoperative pure tone audiogram in predicting the status of ossicular chain in patients with CSOM and to find out the degree and type of hearing loss caused by ossicular chain disruption.

\section{Materials and Methods}

This one-year hospital based observational clinical study was conducted in the Department of Otorhinolaryngology and Head and Neck Surgery, GMERS Medical College, Gandhinagar, Gujarat, from October 2016 to September 2017. A total of 115 patients who presented to the ENT OPD with ear discharge and diagnosed of Chronic suppurative otitis media (both types: tubo-tympanic and attico-antral) who fulfilled the inclusion criteria were included in the study. Written Informed Consent was taken. Permission from Institutional Ethics Committee (IEC) was taken.

All patients were subjected to audiological investigation, radiological investigation, otomicroscopy and or otoendoscopy. Detailed examination under operating microscope and $/ 0^{\circ} / 30^{\circ}$ $(4 \mathrm{~mm})$ endoscope, middle ear status and ossicular chain status was carried out. Pure tone audiometry findings like $A B G$, ACT at 500, 1000, 2000, $4000 \mathrm{~Hz}$ frequencies were noted. All patients underwent tympanoplasty, intraoperative middle ear findings including ossicular status in terms of its presence, mobility, erosion, and continuity of the Malleo-Incudal and Incudo-Stapedial joint was noted and compared with preoperative pure tone audiometry profile findings.

Statistical analysis: Descriptive and inferential statistical analysis has been carried out in the present study. Results on continuous measurements are presented on Mean \pm SD (MinMax) and results on categorical measurements are presented in Number (\%). Significance is assessed at $5 \%$ level of significance. Student t test (two tailed, independent) has been used to find the significance of study parameters on continuous scale between two groups (Inter group analysis) on metric parameters. Chi-square/ Fisher Exact test has been used to find the significance of study parameters on categorical scale between two or more groups, Non-parametric setting for Qualitative data analysis. The Statistical software namely SPSS 18.0, and R environment ver.3.2.2 were used for the analysis of the data and Microsoft word and Excel have been used to generate graphs, tables etc. the results of the study are summarized as below.A $p$ value of $\leq 0.05$ was found statistically significant.

\section{Results}

In this study, total of 115 patients aged between 15-60 years were included with Mean age ranging between $32.91 \pm 11.99$ years. Demographically 74 cases $(64 \%)$ were females and 41 cases (36\%) were males. Majority of the patients belonged to poor socioeconomic background.

Out of 115 patients studied, 52 patients (45.2\%) had left ear disease, followed by 41 patients $(35.7 \%)$ with right ear involved, while 22 patients $(19.1 \%)$ had bilateral ears involved. Majority of the cases $93(81 \%)$ were tubo-tympanic type of CSOM, while 22 cases (19\%) were attico-antral type of CSOM. Mean duration of disease in our study was found to be $8.02 \pm 5.38$ years. The duration of hearing loss was found to be lesser than the duration of ear discharge.

In tubo-tympanic CSOM, 11 patients (11.8\%) had small central perforation, 37 patients $(39.8 \%)$ had moderate central perforation, 34 patients $(36.6 \%)$ had large perforation and 11 patients $(11.8 \%)$ had subtotal perforation. In attico-antral CSOM, 14 patients $(63.6 \%)$ had posterosuperior cholesteatoma and 8 patients $(36.3 \%)$ had attic cholesteatoma. No statistically significant differences were observed with regard to size of perforation and hearing impairment based on tuning fork examination, Most of the patients had moderate to large central perforation in patients with tubo-tympanic CSOM. Most of the patients had moderate degree conductive hearing loss 47 patients $(50.5 \%)$ in tubo-tympanic CSOM. While 5 patients $(22.7 \%)$ had moderate hearing loss and 5 patients $(22.7 \%)$ had moderately severe hearing loss in attico-antral CSOM. Majority of the patients $100(83 \%)$ had conductive hearing loss, and $15(17 \%)$ patients had mixed hearing loss while no patients were found to be having sensorineural hearing loss.

Malleus was found to be the most resistant ossicle, in tubotympanic CSOM malleus was found intact in all 93 patients $(100 \%)$, in attico-antral CSOM malleus was found intact in all 15 patients $(68.18 \%)$, partially eroded in 6 patients $(27.3 \%)$ head eroded in 1 patient, handle eroded in 5 patients, absent in 1 patient $(4.5 \%)$. Incus was observed to be the most common ossicle to erode in cases of CSOM. In our study, Incus was found intact in 83 patients $(89.2 \%)$, partially eroded (lenticular process) in 10 patients $(10.8 \%)$, in tubo-tympanic CSOM, while in attico-antral CSOM Incus was found intact in 1 patient $(4.5 \%)$, partially eroded in 14 patients $(63.7 \%)$, and absent in 7 patients $(31.8 \%)$. Stapes was found intact $n 91$ patients $(97.8 \%)$ and suprastructure was eroded in 2 patients 
(2.2\%) in tubo-tympanic CSOM, while Stapes was found intact n 9 patients $(40.9 \%)$ and suprastructure was eroded in 13 patients $(59.1 \%)$ in attico-antral disease. Malleo-Incudal joint was found intact in 108 patients $(93.9 \%)$, while it was discontinuous in 7 patients $(6.1 \%)$. Incudo-Stapedial joint was found intact in 84 patients $(73.1 \%)$ and discontinuous in 31 patients $(26.9 \%)$. With higher incidence of Incudo-Stapedial joint discontinuity in 21 patients $(95.5 \%)$ in attico-antral type (Table 1).

\begin{tabular}{|c|c|c|c|}
\hline Ossicle status & Attico antral CSOM (n=22) & $\begin{array}{c}\text { Tubo tympanic } \\
\text { CSOM (n=93) }\end{array}$ & Total (n=115) \\
\hline Malleus intact & $15(68.18 \%)$ & $93(100 \%)$ & $108(93.9 \%)$ \\
\hline Malleus erosion & $6(27.3 \%)$ & $0(0 \%)$ & $6(5.2 \%)$ \\
\hline Malleus absent & $1(4.5 \%)$ & $0(0 \%)$ & $1(0.86 \%)$ \\
\hline Incus intact & $1(4.5 \%)$ & $83(89.2 \%)$ & $84(73.1 \%)$ \\
\hline Incus erosion & $14(63.7 \%)$ & $10(10.8 \%)$ & $24(20.9 \%)$ \\
\hline Incus absent & $7(31.8 \%)$ & $0(0 \%)$ & $7(6.1 \%)$ \\
\hline Stapes intact & $9(40.9 \%)$ & $91(97.8 \%)$ & $100(86.9 \%)$ \\
\hline Suprastructure erosion & $13(59.1 \%)$ & $2(2.2 \%)$ & $15(13.1 \%)$ \\
\hline
\end{tabular}

Table 1: Status of individual Ossicles in patients with CSOM.

According to Austin Kartush classification of ossicle erosion, 1 patient $(4.5 \%)$ had intact and mobile ossicular chain i.etype $\mathrm{O}(\mathrm{M}+\mathrm{I}+\mathrm{S}+), 7$ patients $(31.8 \%)$ had type $\mathrm{A}(\mathrm{M}+\mathrm{S}+), 7$ patients $(31.8 \%)$ had type $\mathrm{B}(\mathrm{M}+\mathrm{S}-), 1$ patient $(4.5 \%)$ had type $\mathrm{C}(\mathrm{M}-\mathrm{S}+)$, and 6 patients $(27.3 \%)$ had type D (M-S-) ossicular status out of 22 patients with attico-antral CSOM. In tubotympanic CSOM, 83 patients $(89.2 \%)$ had type $\mathrm{O}(\mathrm{M}+\mathrm{I}+\mathrm{S}+), 8$ patients $(8.6 \%)$ had type $\mathrm{A}(\mathrm{M}+\mathrm{S}+), 2$ patients $(2.2 \%)$ had type B $(\mathrm{M}+\mathrm{S}-), 0$ patients $(0 \%)$ had type $\mathrm{C}(\mathrm{M}-\mathrm{S}+)$, and type D (M-S-) ossicular status out of 93patients (Graph -1).

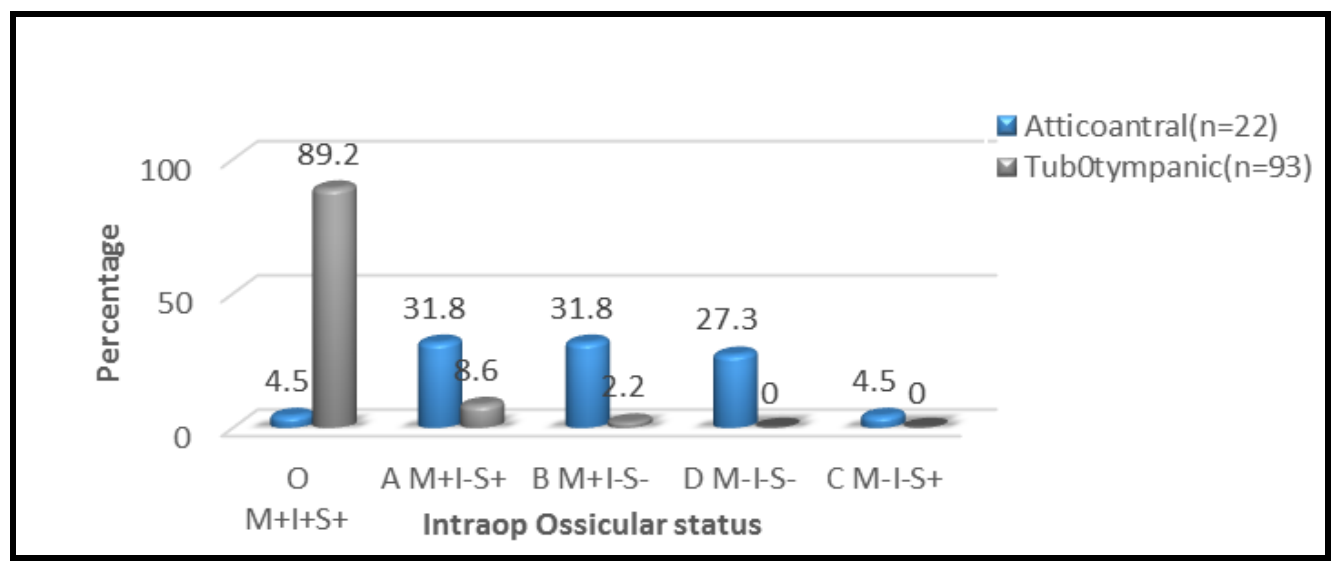

Graph 1: intraoperative ossicular chain status.

When conductive hearing loss was correlated with ossicular chain status for their prediction of ossicular necrosis, the average hearing loss ranged from $31.93 \pm 8.14 \mathrm{~dB}$ to $52.05 \pm 15.66 \mathrm{~dB}$. The average hearing loss was $44.00 \pm 13.48$ $\mathrm{dB}$ with Austin type A ossicular defect, 49.09 $\pm 15.71 \mathrm{~dB}$ with type $\mathrm{B}, 46.14 \pm 17.66 \mathrm{~dB}$ with type $\mathrm{C}$ and $52.05 \pm 15.66 \mathrm{~dB}$ with type D (Table -2). Mean hearing loss with the ossicular chain defects was $48.98 \pm 12.50 \mathrm{~dB}$ with a $\mathrm{p}$ value of $0.001(\mathrm{p}<0.05$ significant). Higher degree of hearing loss was seen with Austin type B and D with a statistically significant $\mathrm{p}=0.026$. Higher degree of hearing loss was seen with two or more ossicle defect than in patients with no or single ossicle defect.

\begin{tabular}{|c|c|}
\hline Austin type & Hearing loss \\
\hline $\mathrm{A}(\mathrm{M}+\mathrm{S}+)$ & $44.00 \pm 13.48 \mathrm{~dB}$ \\
\hline $\mathrm{B}(\mathrm{M}+\mathrm{S}-)$ & $49.09 \pm 15.71 \mathrm{~dB}$ \\
\hline $\mathrm{C}(\mathrm{M}-\mathrm{S}+)$ & $46.14 \pm 17.66 \mathrm{~dB}$ \\
\hline $\mathrm{D}(\mathrm{M}-\mathrm{S}-)$ & $52.05 \pm 15.66 \mathrm{~dB}$ \\
\hline
\end{tabular}

Table 2: Hearing loss associated with Ossicular Defects.

Average ABG was $36.14 \pm 8.88 \mathrm{~dB}$ and $30.93 \pm 7.67 \mathrm{~dB}$ in attico-antral and tubo-tympanic type of CSOM respectively. Average ACT was $48.58 \pm 16.30 \mathrm{~dB}$ and $41.65 \pm 11.12 \mathrm{~dB}$ in attico-antral and tubo-tympanic type of CSOM respectively (Table 3). 


\begin{tabular}{|cc|c|c|c|c|}
\hline & \multicolumn{2}{|c|}{ Disease Type } & \multirow{2}{*}{ Total } & \multirow{2}{*}{ P value } \\
\cline { 2 - 4 } & Atticoantral & Tubotympanic & & \\
\hline & ABG at & & & & $0.017^{*}$ \\
\hline$\bullet$ & $500 \mathrm{~Hz}$ & $38.41 \pm 10.4$ & $33.06 \pm 9.06$ & $34.09 \pm 9.52$ & $0.001^{* *}$ \\
\hline$\bullet$ & $1000 \mathrm{~Hz}$ & $37.27 \pm 10.20$ & $30.22 \pm 8.87$ & $31.57 \pm 9.51$ & 0.132 \\
\hline$\bullet$ & $2000 \mathrm{~Hz}$ & $32.73 \pm 11.10$ & $29.52 \pm 8.34$ & $30.13 \pm 8.97$ & $0.009^{* *}$ \\
\hline & $4000 \mathrm{~Hz}$ & $36.14 \pm 12.62$ & $29.78 \pm 9.38$ & $31.00 \pm 10.33$ & $0.006^{* *}$ \\
\hline & $\mathrm{Avg} \mathrm{ABG} \mathrm{dB}$ & $36.14 \pm 8.88$ & $30.93 \pm 7.67$ & $31.93 \pm 8.14$ & \\
\hline$\bullet$ & $\mathbf{A C T}$ at & & & & $0.048^{*}$ \\
\hline$\bullet$ & $500 \mathrm{~Hz}$ & $49.09 \pm 15.71$ & $42.80 \pm 12.69$ & $44.00 \pm 13.48$ & $0.024^{*}$ \\
\hline$\bullet$ & $1000 \mathrm{~Hz}$ & $47.05 \pm 15.56$ & $40.16 \pm 11.99$ & $41.48 \pm 12.96$ & $0.040^{*}$ \\
\hline$\bullet$ & $2000 \mathrm{~Hz}$ & $46.14 \pm 17.66$ & $39.46 \pm 12.41$ & $40.74 \pm 13.74$ & $0.024^{*}$ \\
\hline & $4000 \mathrm{~Hz}$ & $52.05 \pm 21.80$ & $43.71 \pm 13.49$ & $45.30 \pm 15.66$ & $0.019^{*}$ \\
\hline
\end{tabular}

Table 3: Comparison of ABG and ACT variables according to Disease type.

These values were statistically significant with $\mathrm{p}$ value of 0.006 and 0.019 . In the present study, mean $A B G$ was $38.41 \pm 10.4 \mathrm{~dB}$ at $500 \mathrm{~Hz}, 37.27 \pm 10.20 \mathrm{~dB}$ at $1000 \mathrm{~Hz}$, $32.73 \pm 11.10 \mathrm{~dB}$ at $2000 \mathrm{~Hz}$ and $36.14 \pm 12.62 \mathrm{~dB}$ at $4000 \mathrm{~Hz}$ in attico-antral type of CSOM. Whereas mean ABG was
$33.06 \pm 9.06 \mathrm{~dB}$ at $500 \mathrm{~Hz}, 30.22 \pm 8.87 \mathrm{~dB}$ at $1000 \mathrm{~Hz}$, $29.52 \pm 8.34 \mathrm{~dB}$ at $2000 \mathrm{~Hz}$ and $29.78 \pm 9.38 \mathrm{~dB}$ at $4000 \mathrm{~Hz}$ in tubo-tympanic type of CSOM. These values were statistically significant with $\mathrm{p}$ value of $0.017,0.001,0.009$ and 0.048 , $0.024,0.040$ respectively (Table 4,5).

\begin{tabular}{|c|c|c|c|c|c|}
\hline \multirow{2}{*}{ PTA-ABG (dB) } & \multicolumn{3}{|c|}{ At } & \multicolumn{4}{|c|}{$\mathbf{4 0 0 0 H z}$} & Avg ABG \\
\cline { 2 - 6 } & $\mathbf{5 0 0 H z}$ & $\mathbf{1 0 0 0 H z}$ & $\mathbf{2 0 0 0 H z}$ & $3(2.6 \%)$ & $0(0 \%)$ \\
\hline $10-J a n$ & $0(0 \%)$ & $2(1.7 \%)$ & $3(2.6 \%)$ & $24(20.9 \%)$ & $6(5.2 \%)$ \\
\hline $20-$ Nov & $11(9.6 \%)$ & $19(16.5 \%)$ & $21(18.3 \%)$ & $47(40.9 \%)$ & $52(45.2 \%)$ \\
\hline $21-30$ & $43(37.4 \%)$ & $44(38.3 \%)$ & $48(41.7 \%)$ & $30(26.1 \%)$ & $40(34.8 \%)$ \\
\hline $31-40$ & $39(33.9 \%)$ & $36(31.3 \%)$ & $34(29.6 \%)$ & $8(7 \%)$ & $16(13.9 \%)$ \\
\hline $41-50$ & $20(17.4 \%)$ & $11(9.6 \%)$ & $9(7.8 \%)$ & $3(2.6 \%)$ & $1(0.9 \%)$ \\
\hline $51-60$ & $2(1.7 \%)$ & $3(2.6 \%)$ & $0(0 \%)$ & $0(0 \%)$ & $0(0 \%)$ \\
\hline $61-70$ & $0(0 \%)$ & $0(0 \%)$ & $0(0 \%)$ & $0(0 \%)$ & $0(0 \%)$ \\
\hline$>70$ & $0(0 \%)$ & $0(0 \%)$ & $0(0 \%)$ & $115(100 \%)$ & $115(100 \%)$ \\
\hline Total & $115(100 \%)$ & $115(100 \%)$ & $115(100 \%)$ & $31.00 \pm 10.33$ & $31.93 \pm 8.14$ \\
\hline Mean \pm SD & $34.09 \pm 9.52$ & $31.57 \pm 9.51$ & $30.13 \pm 8.97$ & & \\
\hline
\end{tabular}

Table 4: Distribution of Air Bone Gap at each frequency.

\begin{tabular}{|c|c|c|c|c|c|}
\hline \multirow[b]{2}{*}{ PTA-ACT (dB) } & \multicolumn{5}{|c|}{$\mathbf{A t}$} \\
\hline & $500 \mathrm{~Hz}$ & $1000 \mathrm{~Hz}$ & $2000 \mathrm{~Hz}$ & $4000 \mathrm{~Hz}$ & Avg-ACT \\
\hline 10-Jan & $1(0.9 \%)$ & $0(0 \%)$ & $0(0 \%)$ & $0(0 \%)$ & $0(0 \%)$ \\
\hline $21-30$ & $23(20 \%)$ & $29(25.2 \%)$ & $35(30.4 \%)$ & $30(26.1 \%)$ & $15(13 \%)$ \\
\hline $31-40$ & $34(29.6 \%)$ & $35(30.4 \%)$ & $29(25.2 \%)$ & $30(26.1 \%)$ & $41(35.7 \%)$ \\
\hline $41-50$ & $26(22.6 \%)$ & $23(20 \%)$ & $27(23.5 \%)$ & $23(20 \%)$ & $29(25.2 \%)$ \\
\hline $61-70$ & $3(2.6 \%)$ & $4(3.5 \%)$ & $5(4.3 \%)$ & $7(6.1 \%)$ & $6(5.2 \%)$ \\
\hline$>70$ & $3(2.6 \%)$ & $2(1.7 \%)$ & $3(2.6 \%)$ & $7(6.1 \%)$ & $4(3.5 \%)$ \\
\hline Total & $115(100 \%)$ & $115(100 \%)$ & $115(100 \%)$ & $115(100 \%)$ & $115(100 \%)$ \\
\hline Mean \pm SD & $44.00 \pm 13.48$ & $41.48 \pm 12.96$ & $40.74 \pm 13.74$ & $45.30 \pm 15.66$ & $42.98 \pm 12.50$ \\
\hline
\end{tabular}

Table 5: Distribution of Air Conduction thresholds at each frequency. 
92 patients $(80 \%)$ showed a pure tone audiogram pattern which had parallel air conduction and bone conduction lines, while 16 patients $(13.9 \%)$ showed an upsloping audiogram with higher air bone gap at lower frequencies and 7 patients $(6.1 \%)$ showed downsloping audiogram with higher air bone gap at higher frequencies. In patients with parallel audiogram, 20 patients had ossicular defects with 1 or more ossicular erosion intraoperatively (Austin type $\mathrm{A}$ in 10 patients, type $\mathrm{B}$ in 6 patients, type $\mathrm{C}$ in 1 patient and type $\mathrm{D}$ in 3 patients). In case of upsloping audiogram, 6 patients had ossicular defects (Type $\mathrm{A}$ in 2 patients, type $\mathrm{B}$ in 3 patients, type $\mathrm{D}$ in 1 patient). Whereas in downsloping audiogram 5 patients had ossicular defects (type A in 3 patients, type D in 2 patients. Though all patients with upsloping audiogram showed IncudoStapedial joint discontinuity intraoperatively, the value was not statistically significant (Graph 2).

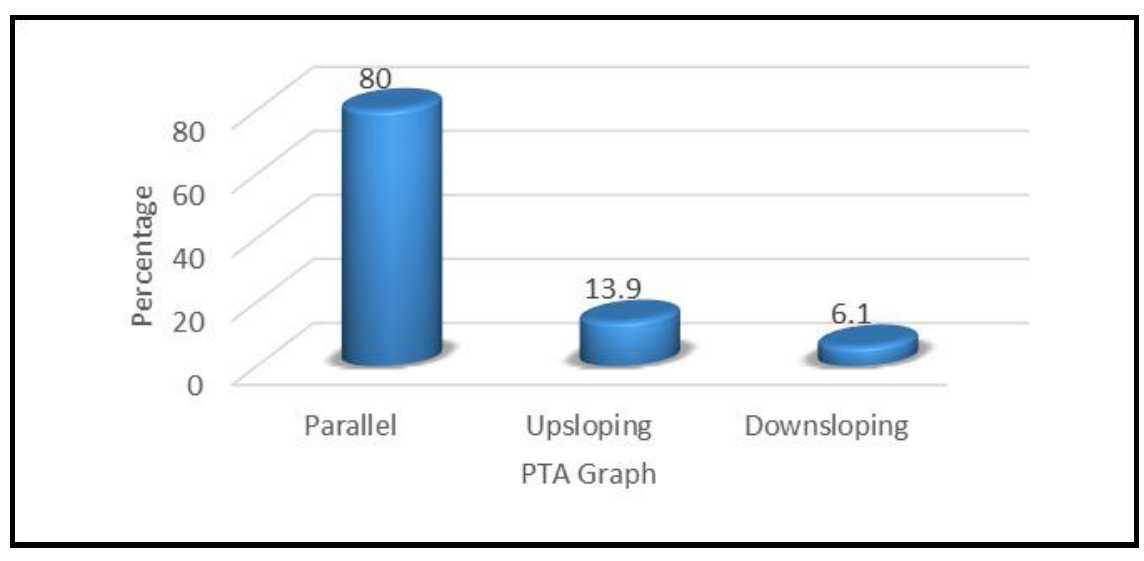

Graph 2: Pattern of Pure tone audiometry graph.

\section{Discussion}

Chronic suppurative otitis media is a major cause of acquired hearing impairment especially in the developing countries. Its social and economic implications are accordingly enormous [12]. Ossicular erosion is the most frequent complication occurring in $>50 \%$ cases of CSOM, more commonly seen with cholesteatoma. Surgery is the treatment modality of choice and tympanoplasty without ossicular reconstruction leads to long term acoustic failure in around 50$60 \%$ patients [7-9]. Preoperative audiograms best detect the presence or absence of ossicular chain defects in the absence of cholesteatoma. Frequency specific air bone gap can predict ossicular discontinuity in chronic suppurative otitis media. The aim of our study is to evaluate frequency specific $A B G$, ACT values of pure tone audiogram graph, and correlate with intraoperative ossicular chain status, to evaluate the effectiveness of PTA in predicting ossicular chain defects preoperatively.

Reconstructive middle ear surgery in patients with CSOM with and without cholesteatoma was introduced with tympanoplasty by Moritz (1952), Zollner (1953, 1955), and Wullstien (1953, 1956) [13]. Few clinical studies have carefully examined the relationship between ossicular erosion and conductive hearing loss. Ryner JC, Carillo et.al. [11] in 2006 explored the association of ossicular discontinuity with ABG cut off values across different frequencies and found out specific cut off values associated with ossicular discontinuity in patients with chronic otitis media.

Jeng et.al. [14] and Carillo et.al. [15] explored the association of ossicular discontinuity with air bone gap. They studied whether preoperative findings such as air bone gap, ear discharge, mastoid pneumatization, and other parameters were predictive of ossicular discontinuity or not. They also found that $\mathrm{ABG}$ was larger in ears with ossicular discontinuity than in those with intact ossicular chain. However, studies of ossicular chain dysfunction must be frequency specific since the ossicular chain and Tympanic membrane have different efficiencies across frequency.Rashid S, Hassanin A et.al. [16] in 2016 in their study evaluated the preoperative predictors for ossicular discontinuity in patients with CSOM, they found that increased pure tone average values at lower frequencies both $1000 \mathrm{~Hz}$ and $2000 \mathrm{~Hz}$ are the most reliable variables associated with ossicular discontinuity.

Correlations between pure tone audiometry and ossicular discontinuity can be modified by the type and degree of tympanic membrane perforation, middle ear polyps, degree ad bilaterality of hearing loss. Granulation tissue and cholesteatoma may be independent predictors of ossicular discontinuity but may alter results of hearing by direct conduction of sound. The air bone gap degree and pattern should be able to predict an ossicular chain dysfunction. Such dysfunction can be in the form of ossicular chain fixation or discontinuity.

In a study done by Carillo 2007 [15], analysed the likelihood ratios and predictive values of preoperative air bone gap levels on the presence of gross ossicular discontinuity among CSOM patients with and without cholesteatoma. He concluded that a narrow air bone gap at lower frequencies (i.e. air bone gap of $20 \mathrm{~dB}$ or less at $500 \mathrm{~Hz}$ and $30 \mathrm{~dB}$ or less at $1000 \mathrm{~Hz}$ ) suggested absence of ossicular discontinuity while air bone gap of $>50 \mathrm{~dB}$ at $500 \mathrm{~Hz},>30 \mathrm{~dB}$ at $2000 \mathrm{~Hz}$ and $>50 \mathrm{~dB}$ at $4000 \mathrm{~Hz}$ best predict presence of ossicular discontinuity in general. In the absence of cholesteatoma, air bone gaps of $<30 \mathrm{~dB}$ at $500 \mathrm{~Hz}$ and $<20 \mathrm{~dB}$ at $1000 \mathrm{~Hz}$ decrease 
the probability of ossicular discontinuity from $32.97 \%$ to $2.54 \%$. A wide air bone gap at higher frequencies (i.e. $>30 \mathrm{~dB}$ at $2000 \mathrm{~Hz}$ and $>40 \mathrm{~dB}$ at $4000 \mathrm{~Hz}$ ) suggested presence of ossicular discontinuity. In our study we found that the $\mathrm{ABG}$ and ACT values at $500 \mathrm{~Hz}, 1000 \mathrm{~Hz}$ and $4000 \mathrm{~Hz}$ were statistically significant with $\mathrm{p}$ value of $0.017,0.001,0.009$ and $0.048,0.024,0.040$ respectively.

Similarly in our study, in the absence of cholesteatoma the mean $\mathrm{ABG}$ was $>30 \mathrm{~dB}$ at $500 \mathrm{~Hz},>30 \mathrm{~dB}$ at $1000 \mathrm{~Hz},>35 \mathrm{~dB}$ at $2000 \mathrm{~Hz},>25 \mathrm{~dB}$ at $4000 \mathrm{~Hz}$ which showed statistically significant $\mathrm{p}$ values. However, in cases with cholesteatoma, the mean $\mathrm{ABG}$ was $>38 \mathrm{Db}$ at $500 \mathrm{~Hz},>30 \mathrm{~dB}$ at $1000 \mathrm{~Hz}$, $>30 \mathrm{~dB}$ at $2000 \mathrm{~Hz},>35 \mathrm{~dB}$ at $4000 \mathrm{~Hz}$. Patients with wide ABG at lower frequencies (upsloping audiogram) showed erosion of incus or discontinuation of Malleo-incudal joint and or Incudo-stapedial Joint, and patients with wide ABG at higher frequencies (downslopingaudiogram) had erosion of 2 or more ossicles and / Incudo-stapedial erosion, stapes supra structure erosion.

Malleus was found to be the most resistant ossicle, and incus the most common ossicle to undergo erosion. These findings were consistent with similar studies [17-20]. When conductive hearing loss was correlated with ossicular chain status for their prediction of ossicular necrosis, the average hearing loss ranged from $31.93 \pm 8.14 \mathrm{~dB}$ to $52.05 \pm 15.66 \mathrm{~dB}$. Mean hearing loss with the ossicular chain defects was $48.98 \pm 12.50 \mathrm{~dB}$ with a $\mathrm{p}$ value of 0.001 ( $\mathrm{p}<0.05$ significant). Higher degree of hearing loss was seen with Austin type B and $\mathrm{D}$ with a statistically significant $\mathrm{p}$ value of 0.026 . From this correlation we can predict to some extent that in cases of absent stapes supra-structure, hearing loss is maximum, though in some cases where factors like cholesteatoma bridging, polyps, granulation tissue, volume of middle ear cleft etc. hearing may be better. These findings suggest average hearing loss was worse in patients with two or three ossicle defects as compared to no ossicular defect or single ossicle defect. Though Frequency specific ABG and ACT values were found to be statistically significant in our study, further studies with higher samples are required to confirm the above findings.

Higher degree of hearing loss is seen with two or more ossicle defect than in patients with no or single ossicle defect. Majority of the patients had conductive hearing loss, with an average of $45 \mathrm{~dB}$.Higher air bone gap and air conduction thresholds at lower frequencies $(500 \mathrm{~Hz}, 1000 \mathrm{~Hz})$, higher degree of conductive hearing loss by pure tone audiometry can predict the presence of ossicular chain dysfunction in CSOM. It is a well-known fact that pathological tissue can transmit sounds bridging the damaged ossicular chain, Functional integrity even in the presence of ossicle erosion, allows sound transmission in cases of cholesteatoma. Pure tone audiogram does not always show the real state of ear transmission system. However, frequency specific $\mathrm{ABG}$ and $\mathrm{ACT}$ can provide a reliable insight into the middle ear transmission, ossicle status and type of ossicle dysfunction which may help the surgeon to pre plan ossicle reconstruction.

\section{Conclusion}

Chronic otitis media is a common cause of acquired hearing impairment in developing countries. Both types of CSOM can cause ossicular chain dysfunction. Pure tone audiometry is the most common, noninvasive, low cost test used to evaluate hearing sensitivity. Knowing the ossicular chain status is very important in patients undergoing tympanoplasty which will help in planning ossicular chain reconstruction. Frequency specific ABG and ACT can predict gross ossicular discontinuity, and varying degrees of ossicular dysfunction preoperatively.

As otorhinolaryngologists, one should understand the concept of middle ear sound transmission system and ossicular reconstruction surgery to give best hearing results to our patients.

Funding: This research did not receive any specific grant from any funding agencies in the public, commercial, or not for profit sectors.

\section{Conflict of Interest: None declared}

Ethical Approval: The study was approved by the Institutional Ethics Committee.

\section{Abbreviations}

CSOM: Chronic Suppurative Otitis Media,

PTA: $\quad$ Pure Tone Audiometry,

ABG: $\quad$ Air Bone Gap,

ACT: $\quad$ Air Conduction Threshold.

\section{References}

1. Acuin J (2004) Chronic suppurative Otitis Media Burden of illness and management options. Geneva: World Health Organization.

2. Slattery WH (2003) Pathology and Clinical Course of inflammatory diseases of the middle ear. In. Glasscock ME, Gulya AJ (eds). Glasscock-Shambaugh Surgery of the Ear. 6thedn. Reed Elsevier India Pvt Ltd, New Delhi. P428-429.

3. Hassan H, Rashid S, Aisha L, Elsaadi A, Abdulkarim H, et.al. (2015) Ossicular chain erosion in Chronic Suppurative Otitis Media. Otolaryngol (Sunnyvale) 5: 203-207.

4. Anglitoiu A, Balica N, Lupescu S, Vintila R, Cotulbea (2011) Ossicular chain status in the Otological Pathology of the ENT Clinic. Timisoara. Medicine in Evolution. 2011; 17: 344-351.

5. Proctor B (1964) The development of middle ear spaces and their surgical significance. J LaryngolOtol 78: 631648.

6. Bojrab DI, Balough BJ (2003) Surgical Anatomy of the Temporal Bone and Dissection Guide. In. Glasscock ME, Gulya AJ (eds). Glasscock-Shambaugh Surgery of the 
Ear. 5thedn (2003). Reed Elsevier India Pvt Ltd, New Delhi. p778.

7. Merchant SN, Rosowski JJ (2003) Auditory physiology. In:Glasscock ME, Gulya AJ (eds). GlasscockShambaughSurgery of the ear, 5th edn (2003). Reed Elsevier India Pvt. Ltd, New Delhi. p70.

8. Iniguez $\mathrm{CR}$, Alobid $\mathrm{I}$, Bores $\mathrm{DA}$, Menendez CLM, Caballero BM, et.al. (2010) Type III Tympanoplasty with Titanium Total Ossicular Replacement Prosthesis: Anatomic and Functional results. OtolNeurotol 31: 409414.

9. Yung M, Vowler SC (2006) Long term Results in Ossiculoplasty: An Analysis of Prognostic Factors. OtolNeurotol 27: 874-881.

10. Hosny S, El-Anwar M, Abd-Elhady M, Khazhak A, ElFeky A (2014) Outcomes of Myringoplasty in Dry and Wet Ears. Int Adv Otol 10: 256-259.

11. Ryner JCC, Nathaniel WY, Generoso TA (2006) 'Relationship of Pure tone audiometry and Ossicular Discontinuity in Chronic Otitis Media'. Phill J of Otolaryngol Head Neck Surg 21: 5-10.

12. Salma AA, Azhar H, Muhammad EK, Muhammed M (2009) Analytical study of Ossicular chain in middle ear Cholesteatoma. Annals of Otorhinolaryngology 15: 134137.

13. Ryner JCC, Nathaniel W, Generoso T (2007) Probabilities of Ossicular Discontinuity in Chronic Suppurative Otitis
Media using Pure Tone Audiometry. Otol and Neurotol 28: 1034-1037.

14. Jeng FC, Tsai MH, Brown CJ (2003) Relationship pf preoperative findings and ossicular discontinuity in Chronic Otitis Media. Otol and Neurotol 24: 29-32.

15. Ryner JCC, Nathaniel W, Generoso T (2007) Probabilities of Ossicular Discontinuity in Chronic Suppurative Otitis Media using Pure Tone Audiometry. Otol and Neurotol 28: 1034-1037.

16. Rashid S, Hassan H, Hassanin A, Waqar A, Aisha L, Ali A, Abdulsalam A (2016) Preoperative predictors in Chronic Suppurative Otitis Media for Ossicular chain discontinuity - A cross sectional study. AudiolNeurotol 21: 231-236.

17. Udaipurwala IH, Iqbal K, Saqulain G, Jalisi M (1994) Pathlogical profile in chronic suppurative otitis media the regional experience. J Pak Med Assoc 44: 235-237.

18. Alireza KY, Babak S, Mojtaba F, Hamidreza S (2011) Association between Audiometric profile and Intraoperative findings in patients with Chronic Suppurative Otitis Media. Irn J of Otorhinolaryngol 23: $37-42$.

19. Austin DF (1971) Ossicular reconstruction. Arch Otolaryngol 94: 525-535.

20. Sade J, Berco E, Buyanover D, Brown M (1981) Ossicular Damage in Chronic Middle Ear Inflammation. Acta Otolaryngol 92: 273-283. Otorhinolaryngology - Head and Neck: AOHNS-101 